\title{
Strength Assessment of Fan Blade with Different Materials
}

\author{
Polyminna Dileep ${ }^{1}$, G Rajkumar ${ }^{1}$, C. Mohan Naidu²
}

${ }^{1}$ M. Tech Scholar, Department of Mechanical Engineering, SKD Engineering College, Gooty, Andhra Pradesh, India

${ }^{2}$ Associate Professor, HOD, Department of Mechanical Engineering, SKD Engineering College, Gooty, Andhra Pradesh, India

ABSTRACT

Weight reduction of turbofan engines is one of the main concerns of aero engine manufacturers in order to cut fuel burn. To achieve higher fuel efficiency, aero engine manufacturers develop turbofans with higher bypass ratio, which can only be achieved with larger (and heavier) fan sections. This makes weight reduction in fan components a major consideration and becomes a key driver for the use of composite materials in future engines. The objective of this project is to design, perform structural analysis and optimization of a Composite fan blade. Development of a fan blade is comparable to a future large aircraft engine fan blade. This thesis is about the structural analysis of a composite fan blade with a honeycomb sandwich construction with a polymer matrix composite and honeycomb Aluminium core compared with baseline solid basic fan blade made of titanium. The focus of this work is to design the sandwich composite blade with honeycomb core and conduct static and dynamic analysis.

Keywords : Thermodynamic, Brayton- Cycle, RB211, JTBD, computational fluid dynamics, PROPFAN, Low Pressure Compressor, High Pressure Compressor, High Pressure Turbine, Low Pressure Turbine , Fibre-

Reinforced Polymer

\section{INTRODUCTION}

Thermodynamic cycles can be divided into two general categories: power cycles, which produce a net power output, and refrigeration and heat pump cycles, which consume a net power input. The thermodynamic power cycles can be categorized as gas cycles and vapour cycles. In gas cycles, the working fluid remains in the gas phase throughout the entire cycle. In vapour cycles, the working fluid exits as a vapour during one part of the cycle and as a liquid during another part of the cycle. Internal combustion engines and gas turbines undergo gas power cycle. The two major application areas of gasturbine engines are aircraft propulsion and electric power generation.
BRAYTON- CYCLE

Gas-turbines usually operate on an open cycle, shown on the left.

- A compressor takes in fresh ambient air (state 1), compresses it to a higher temperature and pressure (state 2).

- Fuel and the higher pressure air from compressor are sent to a combustion chamber, where fuel is burned at constant pressure. The resulting high temperature gases are sent to a turbine (state 3 ).

- The high temperature gases expand to the ambient pressure (state 4 ) in the turbine and produce power.

- The exhaust gases leave the turbine. 
Part of the work generated by the turbine is sent to drive the compressor. The fraction of the turbine work used to drive the compressor is called the back work ratio. Since fresh air enters the compressor at the beginning and exhaust are thrown out at the end, this cycle is an open cycle.

By utilizing the air-standard assumptions, replacing the combustion process by a constant pressure heat addition process, and replacing the exhaust discharging process by a constant pressure heat rejection process, the open cycle described above can be modeled as a closed cycle, called ideal Brayton cycle. The ideal Brayton cycle is made up of four internally reversible processes.

- 1-2 Isentropic compression (in a compressor)

- 2-3 Constant pressure heat addition

- 3-4 Isentropic expansion (in a turbine)

- 4-1 Constant pressure heat rejection
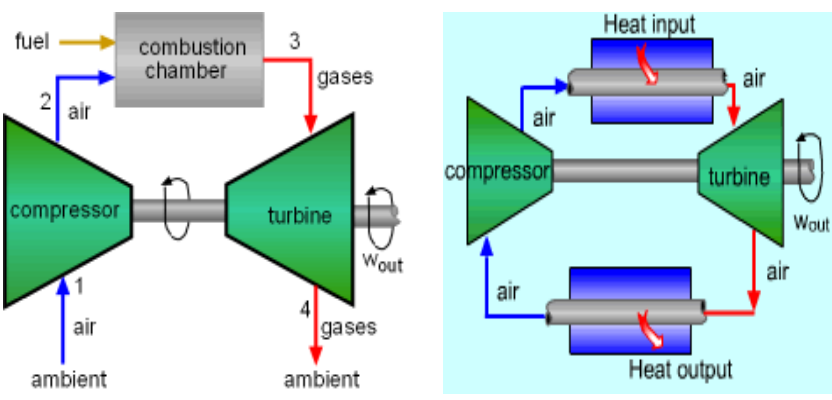

Brayton- Cycle

Jet engines, which are also called gas turbines, work by sucking air into the front of the engine using a fan. From there, the engine compresses the air, mixes fuel with it, ignites the fuel/air mixture, and shoots it out the back of the engine, creating thrust. Basically, a turbojet engine forms the core of the turbofan, the core contains the diffuser, compressor, burner, turbine, and nozzle as shown in Fig. However, in the turbofan engine, the turbine drives not only the compressor, but also a large fan external to the core. The fan itself is contained in a shroud that is wrapped around the core. The flow through a turbofan engine is split into two paths. One passes through the fan and flows externally over the core; this air is processed only by the fan, which is acting in the manner of a sophisticated, shrouded propeller. The propulsive thrust obtained from this flow through the fan is generated with an efficiency approaching that of a propeller. The second air path is through the core itself. The propulsive thrust is obtained from the flow through the core is generated with an efficiency associated with a turbojet. The overall propulsive efficiency of a turbofan is therefore a compromise between that of a propeller and that of a turbojet. This compromise has been found to be quite successful. The vast majority of jet propelled airplanes today are powered by turbofan engines.

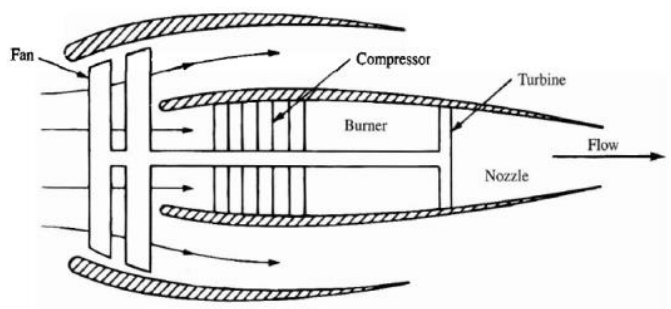

Schematic Jet Engine

An important parameter of a turbofan engine is the bypass ratio, defined as the mass flow passing through the fan, externally to the core divided by the mass flow through the core itself. Everything else being equal, the higher the bypass ratio, the higher the propulsive efficiency. For the large turbofan engines that power airplanes such as the Boeing 747, for example, the Rolls-Royce RB211 and the Pratt \& Whitney JTBD, the bypass ratios are on the order of 5 . Typical values of the thrust specific fuel consumption for these turbofan engines are $0.6 \mathrm{lb} /(\mathrm{lb} \mathrm{h})$ almost half that of a conventional turbojet engine. Fan blades have been growing as jet engines have been getting bigger each fan blade carries the equivalent of nine double-decker buses and swallows the volume of a squash court every second. Advances in computational fluid dynamics (CFD) modelling have permitted complex, 3D curved shapes with very wide chord, keeping the fan capabilities while minimizing the blade count to lower costs. Coincidentally, the bypass ratio grew to achieve higher propulsive 
efficiency and the fan diameter increased. Thus reducing weight and increasing efficiency fan blade is necessary. The thrust of a typical jetliner engine went from 5,000 lbf $(22,000 \mathrm{~N}$ ) (de Havilland Ghost turbojet) in the $1950 \mathrm{~s}$ to $115,000 \mathrm{lbf}(510,000 \mathrm{~N})$ (General Electric GE90 turbofan) in the 1990s, and their reliability went from 40 in-flight shutdowns per 100,000 engine flight hours to less than one in the late 1990s. This, combined with greatly decreased fuel consumption, permitted routine transatlantic flight by twin-engine airliners by the turn of the century, where before a similar journey would have required multiple fuel stops.

\section{TYPES OF JET ENGINES}

There are a large number of different types of jet engines, all of which achieve forward thrust from the principle of jet propulsion.

\section{AIR BREATHING}

Commonly aircraft are propelled by air breathing jet engines. Most air breathing jet engines that are in use are turbofan jet engines, which give good efficiency at speeds just below the speed of sound.

\section{TURBINE POWERED}

Gas turbines are rotary engines that extract energy from a flow of combustion gas. They have an upstream compressor coupled to a downstream turbine with a combustion chamber in-between. In aircraft engines, those three core components are often called the "gas generator." There are many different variations of gas turbines, but they all use a gas generator system of some type.

\section{TURBOJET}

\section{Turbojet Engine:}

A turbojet engine is a gas turbine engine that works by compressing air with an inlet and a compressor (axial, centrifugal, or both), mixing fuel with the compressed air, burning the mixture in the combustor, and then passing the hot, high pressure air through a turbine and a nozzle. The compressor is powered by the turbine, which extracts energy from the expanding gas passing through it. The engine converts internal energy in the fuel to kinetic energy in the exhaust, producing thrust. All the air ingested by the inlet is passed through the compressor, combustor, and turbine, unlike the turbofan engine described below.

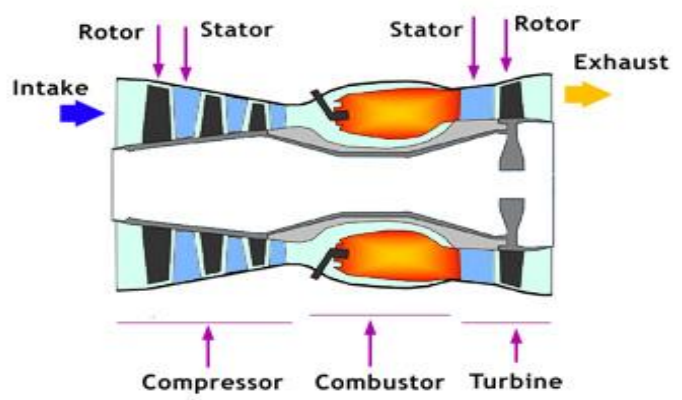

Turbojet Engine

\section{Turbofan:}

Turbofans differ from turbojets in that they have an additional fan at the front of the engine, which accelerates air in a duct bypassing the core gas turbine engine. Compared to a turbojet of identical thrust, a turbofan has a much larger air mass flow rate. Turbofans are the dominant engine type for medium and long-range airliners.

The comparatively large frontal fan has several effects. The main effect is that the output of the engine as a whole has a much higher mass per second, and therefore generates much more thrust, despite not having ignited much of its airflow. Also, because the additional air has not been ignited, no extra fuel is needed to provide this thrust. The slower average velocity of the mixed exhaust air (low specific thrust) is also less wasteful of energy for subsonic flight, and allows the engine to be more efficient and much quieter, while the fan also allows greater thrust to be available at slow speeds. Together, the thrust produced by the fan and core are much more fuel efficient, and provides a much higher output, than could be produced by the core alone. 


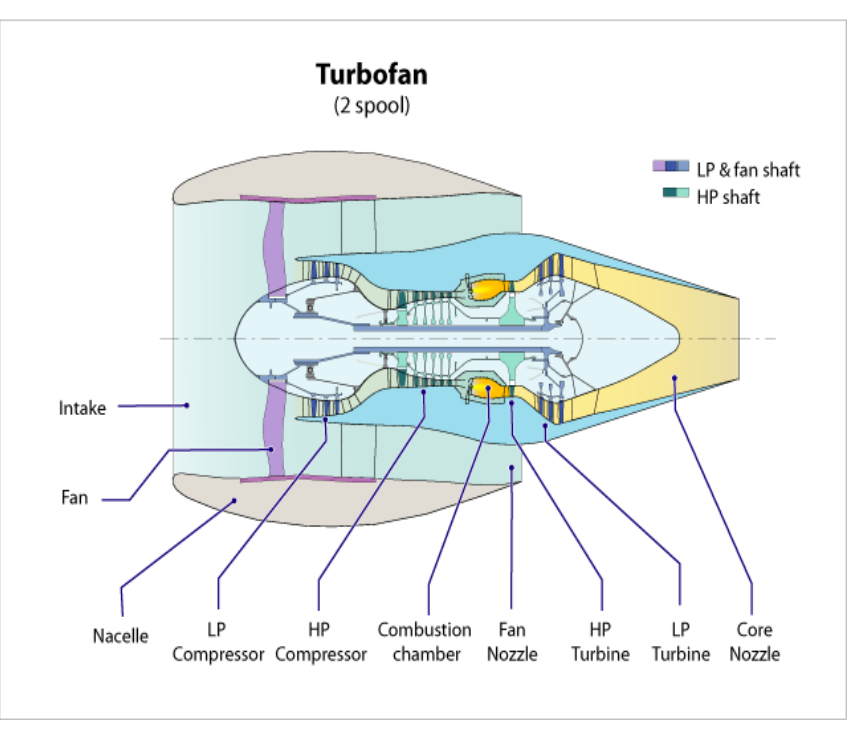

Turbofan

Because of these distinctions, turbofan engine designs are often categorized as low-bypass or high-bypass, depending upon the amount of air which bypasses the core of the engine. Low-bypass turbofans have a bypass ratio of around 2:1 or less, meaning that for each kilogram of air that passes through the core of the engine, two kilograms or less of air bypass the core.[citation needed] Low-bypass turbofans often use a mixed exhaust nozzle meaning that the bypassed flow and the core flow exit from the same nozzle. High-bypass turbofans often have ratios from 4:1 up to 8:1, with the Rolls-Royce Trent XWB approaching 10:1

\section{TURBOPROP AND TURBOSHAFT}

\section{Turboprop Engine:}

Turboprop engines are jet engine derivatives, still gas turbines that extract work from the hot-exhaust jet to turn a rotating shaft, which is then used to produce thrust by some other means. While not strictly jet engines in that they rely on an auxiliary mechanism to produce thrust, turboprops are very similar to other turbine-based jet engines, and are often described as such.
In turboprop engines, a portion of the engine's thrust is produced by spinning a propeller, rather than relying solely on high-speed jet exhaust. As their jet thrust is augmented by a propeller, turboprops are occasionally referred to as a type of hybrid jet engine. They are quite similar to turbofans in many respects, except that they use a traditional propeller to provide the majority of thrust, rather than a ducted fan. Both fans and propellers are powered the same way, although most turboprops use gear-reduction between the turbine and the propeller (geared turbofans also feature gear reduction). While many turboprops generate the majority of their thrust with the propeller, the hot-jet exhaust is an important design point, and maximum thrust is obtained by matching thrust contributions of the propeller to the hot jet. Turboprops generally have better performance than turbojets or turbofans at low speeds where propeller efficiency is high, but become increasingly noisy and inefficient at high speeds.

Turbo shaft engines are very similar to turboprops, differing in that nearly all energy in the exhaust is extracted to spin the rotating shaft, which is used to power machinery rather than a propeller, they therefore generate little to no jet thrust and are often used to power helicopters.
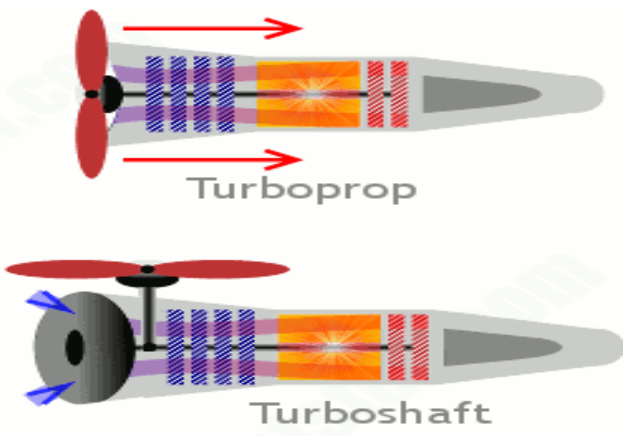

Turboprop Engine

\section{PROPFAN}

\section{A Propfan Engine:}

A propfan engine (also called "un-ducted fan", "open rotor", or "ultra-high bypass") is a jet engine that uses 
its gas generator to power an exposed fan, similar to turboprop engines. Like turboprop engines, propfans generate most of their thrust from the propeller and not the exhaust jet. The primary difference between turboprop and propfan design is that the propeller blades on a propfan are highly swept to allow them to operate at speeds around Mach 0.8, which is competitive with modern commercial turbofans. These engines have the fuel efficiency advantages of turboprops with the performance capability of commercial turbofans. While significant research and testing (including flight testing) has been conducted on propfans, none have entered production.

\section{Ram Powered:}

Ram powered jet engines are air breathing engines similar to gas turbine engines and they both follow the Brayton cycle. Gas turbine and ram powered engines differ, however, in how they compress the incoming airflow. Whereas gas turbine engines use axial or centrifugal compressors to compress incoming air, ram engines rely only on air compressed through the inlet or diffuser. Ram powered engines are considered the most simple type of air breathing jet engine because they can contain no moving parts.

\section{Ramjet:}

Ramjets are the most basic type of ram powered jet engines. They consist of three sections; an inlet to compress incoming air, a combustor to inject and combust fuel, and a nozzle to expel the hot gases and produce thrust. Ramjets require a relatively high speed to efficiently compress the incoming air, so ramjets cannot operate at a standstill and they are most efficient at supersonic speeds. A key trait of ramjet engines is that combustion is done at subsonic speeds. The supersonic incoming air is dramatically slowed through the inlet, where it is then combusted at the much slower, subsonic, speeds. The faster the incoming air is, however, the less efficient it becomes to slow it to subsonic speeds. Therefore, ramjet engines are limited to approximately Mach 5.

\section{Scramjet:}

Scramjets are mechanically very similar to ramjets. Like a ramjet, they consist of an inlet, a combustor, and a nozzle. The primary difference between ramjets and scramjets is that scramjets do not slow the oncoming airflow to subsonic speeds for combustion, they use supersonic combustion instead. The name "scramjet" comes from "Supersonic Combusting Ramjet." Since scramjets use supersonic combustion, they can operate at speeds above Mach 6 where traditional ramjets are too inefficient. Another difference between ramjets and scramjets comes from how each type of engine compresses the oncoming airflow: while the inlet provides most of the compression for ramjets, the high speeds at which scramjets operate allow them to take advantage of the compression generated by shock waves, primarily oblique shocks. Very few scramjet engines have ever been built and flown. In May 2010 the Boeing X-51 set the endurance record for the longest scramjet burn at over 200 seconds.

\section{USES}

Jet engines power jet aircraft, cruise missiles and unmanned aerial vehicles. In the form of rocket engines they power fireworks, model rocketry, spaceflight, and military missiles. Jet engines have propelled high speed cars, particularly drag racers, with the all-time record held by a rocket car. A turbofan powered car, ThrustSSC, currently holds the land speed record. Jet engine designs are frequently modified for non-aircraft applications, as industrial gas turbines or marine power plants. These are used in electrical power generation, for powering water, natural gas, or oil pumps, and providing propulsion for ships and locomotives. Industrial gas turbines can create up to 50,000 shaft horsepower. Many of these engines are derived from older military turbojets such as the Pratt \& Whitney J57 and J75 models. 
There is also a derivative of the P\&W JT8D lowbypass turbofan that creates up to $35,000 \mathrm{HP}$.

\section{TURBOFAN ENGINE}

Most modern jet engines are turbofans. The low pressure compressor (LPC), usually known as a fan, compresses air into a bypass duct whilst its inner portion supercharges the core compressor. The fan is often an integral part of a multi-stage core LPC. The bypass airflow either passes to a separate 'cold nozzle' or mixes with low pressure turbine exhaust gases, before expanding through a 'mixed flow nozzle'.

In the 1960s there was little difference between civil and military jet engines, apart from the use of afterburning in some (supersonic) applications. Today, turbofans are used for airliners because they have an exhaust speed that is better matched to the subsonic flight speed of the airliner. At airliner flight speeds, the exhaust speed from a turbojet engine is excessively high and wastes energy. The lower exhaust speed from a turbofan gives better fuel consumption. The increased airflow from the fan gives higher thrust at low speeds. The lower exhaust speed also gives much lower jet noise. Thus civil turbofans today have a low specific thrust (net thrust divided by airflow) to keep jet noise to a minimum and to improve fuel efficiency. Consequently the bypass ratio (bypass flow divided by core flow) is relatively high (ratios from 4:1 up to 8:1 are common). Only a single fan stage is required, because a low specific thrust implies a low fan pressure ratio.

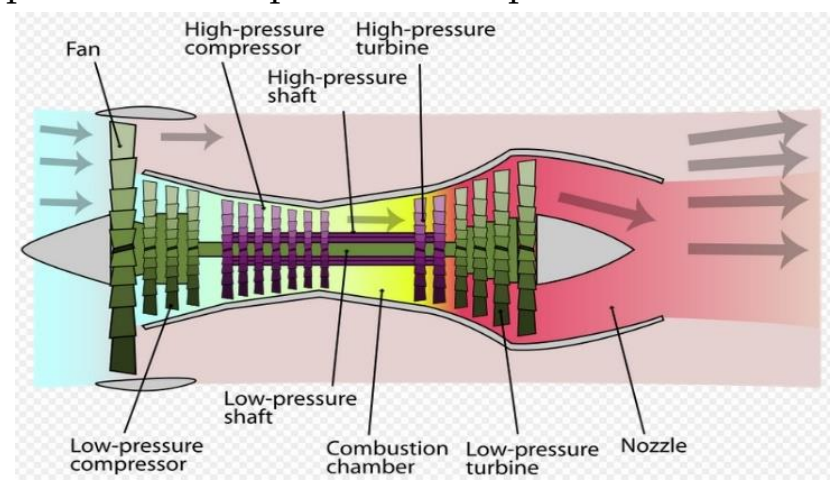

Components of Jet Engine

\section{Air Intake/Ingestion}

The fan is responsible for producing the majority of the thrust generated by a turbofan engine and is easily visible when looking at the front of the engine, as seen in Fig. The fan is directly connected to the low pressure compressor (LPC) and the low pressure turbine (LPT) by way of a shaft known as the low pressure shaft. The fan is station 1 in Fig. 1.6. Ambient air enters the engine by passing through the fan. Most of the air that passes through the fan travels around the core of the engine (the centre of the engine where the compressor, combustor, turbine, and exhaust nozzle are located). This air that travels around the core is known as bypass air. Bypass air is accelerated out of the back of the engine by the fan thereby creating thrust. It never interacts with the compressor, combustor, turbine, or exhaust nozzle. The remaining air enters the core of the engine. This air has been somewhat accelerated by the fan, and immediately enters the low pressure compressor. 2 . Compression The purpose of compression is to prepare the air for combustion by adding energy in the form of pressure and heat. The compressor is divided into two portions: the low pressure compressor, mentioned above, and the high pressure compressor. The compressor is station 2 in Fig. 7. Both compressors function in a similar manner; however, they interact with different parts of the turbofan engine.

\section{The Low Pressure Compressor (LPC)}

The LPC is directly connected to the fan and the low pressure turbine (LPT) by the low pressure shaft. The LPC has rows of spinning blades which push the air further back into the engine. As the air is being forced rearward, the LPC's cross sectional area decreases, causing the volume of air to decrease. From the ideal gas law, this implies that the air is becoming pressurized and the temperature is increasing. Immediately after the air passes through the LPC, it enters the high pressure compressor. 


\section{The High Pressure Compressor (HPC)}

The high pressure compressor, or HPC, is located directly downstream of the LPC and directly upstream of the combustor. The HPC is connected directly to the high pressure turbine by the high pressure shaft. Like the LPC, the HPC has rows of spinning blades which force the air flow rearward into a higher pressure and higher temperature state due to a decrease in volume. The HPC typically has more rows of blades when compared to the LPC. Air exiting the HPC has a high temperature and pressure and is now ready for combustion.

\section{Combustion}

Combustion occurs within the combustor, a stationary chamber within the core of the engine, which is station 3 in Fig. 1.6. The combustor is directly downstream of the HPC and directly upstream of the high pressure turbine. The purpose of the combustor is to add even more energy to the air flow by way of heat addition. Within the combustor, fuel is injected and mixed with the air. This fuel-air mixture is then ignited, creating a dramatic increase in temperature and energizing the flow, propelling it rearward towards the high pressure turbine.

\section{Expansion}

Expansion occurs within the high pressure and low pressure turbines. The turbines are station. Similar in appearance to the compressors, the turbines have rows of blades which spin. The purpose of the turbines is to extract energy from the flow which is then used to spin the compressors and the fan. The spinning fan draws more air through the core of the engine which continues the entire process, and it pulls more bypass air around the engine, generating continuous thrust.

\section{The High Pressure Turbine (HPT)}

The high pressure turbine, or HPT, is located directly downstream of the combustor and directly upstream of the low pressure turbine. The HPT is driven by the high pressure air that passes through it. The HPT's cross sectional area is initially small and then increases downstream. This change in area allows the air to expand, increasing in volume thereby decreasing in pressure and temperature. This decrease in pressure and temperature, along with the energy used to spin the turbine, correspond to a decrease in the overall energy in the air flow. Air exiting the HPT is significantly cooler and less pressurized than the air entering; however, it still has viable energy which will be extracted by the low pressure turbine. As mentioned earlier, the HPT is connected to the HPC by the high pressure shaft. The high pressure shaft spins the HPC when the HPT is spun by the air passing through it. This interaction ensures that the HPC will be pulling air into the combustor continuously, thus feeding the HPT highly energized, combusted air continuously.

\section{The Low Pressure Turbine (LPT)}

The low pressure turbine, or LPT, is located directly downstream of the HPT and directly upstream of the exhaust nozzle. The LPT functions exactly as the HPT does; however, it is connected to the LPC and the fan via the low pressure shaft. Therefore, when the LPT is driven by the air passing through it, is also drives the LPC and the fan. When the LPC is spinning, it provides the HPC with air to feed to the combustor. When the fan is spinning, it provides the LPC with air to feed to the HPC, and it produces thrust by accelerating bypass air out of the engine. Air exiting the LPT is significantly cooler than when entering, but it is still hotter than the ambient air. This hot air exits the LPT and immediately enters the exhaust nozzle. 


\section{Exhaust}

The exhaust nozzle is located directly downstream of the LPT and it is the last component that the air flow touches before exiting the engine. An example of an exhaust nozzle can be seen in Fig. 2. The exhaust nozzle is at station 5 in Fig. 2 and it is stationary, like the combustion chamber. The purpose of the exhaust nozzle is to propel the core flow out of the engine, providing additional thrust. This is accomplished by way of its geometry or shape. The nozzle also helps regulate pressures within the engine to keep the other components functioning properly and efficiently

\section{FIBRE-REINFORCED POL YMER (FRP)}

Fibre-reinforced polymer (FRP), also Fibrereinforced plastic, is a composite material made of a polymer matrix reinforced with fibres. The fibres are usually glass, carbon, or aramid, al- though other fibres such as paper or wood or asbestos have been sometimes used. The polymer is usually an epoxy, vinyl ester or polyester thermosetting plastic, and phenol formaldehyde resins are still in use. FRPs are commonly used in the aerospace, automotive, marine, and construction industries. Composite materials are engineered or naturally occurring materials made from two or more constituent materials with significantly different physical or chemical properties which remain separate and distinct within the finished structure. Most composites have strong, stiff fibres in a matrix which is weaker and less stiff. The objective is usually to make a component which is strong and stiff, often with a low density.

Such cases include the use of bonded FRP sheets or plates in repair and strengthening of concrete structures, and the use of FRP meshes or textiles or fabrics in thin cement products. The cost of repair and rehabilitation of a structure is always, in relative terms, substantially higher than the cost of the initial structure. Repair generally requires a relatively small volume of repair materials but a relatively high commitment in labour. Moreover the cost of labour in developed countries is so high that the cost of material becomes secondary. Thus the highest the performance and durability of the repair material is, the more cost-effective is the repair. This implies that material cost is not really an issue in repair and that the fact that FRP repair materials are costly is not a constraining drawback. When considering only energy and material resources it appears, on the surface, the argument for FRP composites in a sustainable built environment is questionable. However, such a conclusion needs to be evaluated in terms of potential advantages present in use of FRP composites related to considerations such as:

- Higher strength

- Lighter weight

- Higher performance

- Longer lasting

- Rehabilitating existing structures and extending their life

- Seismic upgrades

- Defence systems

- Space systems

- Ocean environments

\section{FAN BLADE}

On average 30 percent of the tot all engine weight is added by the propulsor, which comprises the fan blades and related components such as the fan casing, disc and outlet guide vanes. Traditionally most parts of the propulsor are made of metallic materials; titanium alloys are nowadays the most common choice for the fan blades and the disc, while highly ductile steel, titanium, aluminium and magnesium are often used for main parts of the casing. Significant weight savings can be achieved by replacing these metallic materials by fibre reinforced composite materials which are a mixture of very strong and stiff fibres carrying the major part of the load and a so 
called matrix material which holds together the fibres and distributes the load between them.

Due to this property of the matrix material the strength of the composite can exceed the strength of the individual constituents. For operating temperatures below $200^{\circ} \mathrm{C}$ a widely used type of fibre reinforced composite material is carbon-fibrereinforced plastic (CFRP). The density of CFRP is typically about $66 \%$ lower than the density of titanium, while providing a comparable strength. The resulting strength to weight ratio makes these materials particularly attractive for the usage in turbofan engines. Fan blades made of fibre reinforced composite materials are a key element for the weight reduction of the entire propulsor, since lighter fan blades allow the supporting structural components, including the disc, to become lighter. Additionally the fan casing can be reduced in weight as well since its task to contain the blades in case of a blade failure can be accomplished using less material than would be needed in the case of heavier metallic blades. The design of composite fan blades is a multidisciplinary problem; e.g. composite blades tend to become thicker than hollow metallic ones in order to meet the structural performance targets but this affects the aerodynamic performance (efficiency).

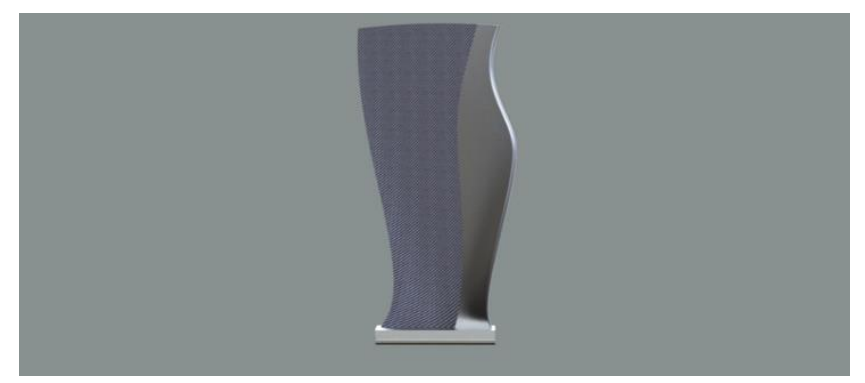

Fan Blade

As shown in Fig. the fan blades are given different lean angles at different cross sections and it is swept in order to avoid bending of the fan and achieve maximum aero dynamic performance.

\section{HISTORY OF FAN BLADE}

Fan blades for high by pass aero-engines were, for many years, manufactured from solid titanium alloy forgings and were designed with mid span snubbers to control vibration. However, snubbers impeded airflow and reduced aerodynamic efficiency, penalising fuel consumption. Modern designs have deleted the snubber to provide a more aerodynamically efficient aerofoil, and increased the blade chord for mechanical stability, reducing the number of blades by approximately one third. This has been achieved at reduced weight with a hollow construction and an internal core.

For both snubbered and wide chord blades, a conventional fine grain titanium alloy - 6\% aluminium and $4 \%$ vanadium (Ti6Al4V) is used. It is simple in terms of chemistry, with the aluminium offering strengthening and low density, and the vanadium making hot working of the material easier. It is used for discs and compressor blades up to about $350^{\circ} \mathrm{C}$, but excellent superplastic forming and solid state diffusion bonding capabilities make it particularly suitable for the wide chord blade.

For the first generation design the joints are made by a transient liquid phase diffusion bonding process, whereas the second generation employs solid state diffusion bonding in association with superplastic forming of the assembly. The cavity of the bonded construction is inflated at elevated temperatures between contoured metal dies using an inert gas to expand the core and simultaneously develop the blade's external aerodynamic profile.

The reliability of these wide chord blades has been second to none. The step in technology produced a major competitive advantage and ten years passed before an equivalent design appeared from a manufacturer other than Rolls Royce. This service record was the result of thorough development 
testing. Fatigue testing in both low and high cycle modes was essential. Groups of blades were repeatedly accelerated to maximum speed in vacuum to establish low cycle endurance, and high cycle fatigue was investigated on a static vibration rig up to the maximum stress levels likely to be encountered in service.

With a large forward facing area, resistance to bird ingestion is required. Ingestion of a number of medium size birds has to be demonstrated by running an engine at take-off power and requiring it to ingest four birds within the space of one second. The engine continued to deliver power, accelerating and decelerating for a total period of thirty minutes to simulate the likely operating procedure following a severe ingestion incident.

In the very unlikely event of a blade mechanical failure, the engine has to be shown to be structurally sound and to contain all the debris, even if the failure occurs at maximum power. Containment in modern engines is achieved with aluminium or titanium casings through which the blade fragments can penetrate, to be caught in external windings of Kevlar. As an indication of the benefits of materials development and design enhancements, engines incorporating the wide chord blade have fan modules that are approximately $24 \%$ lighter and an engine which is $7 \%$ lighter (typically the Trent 800 engine as used in the Boeing 777).

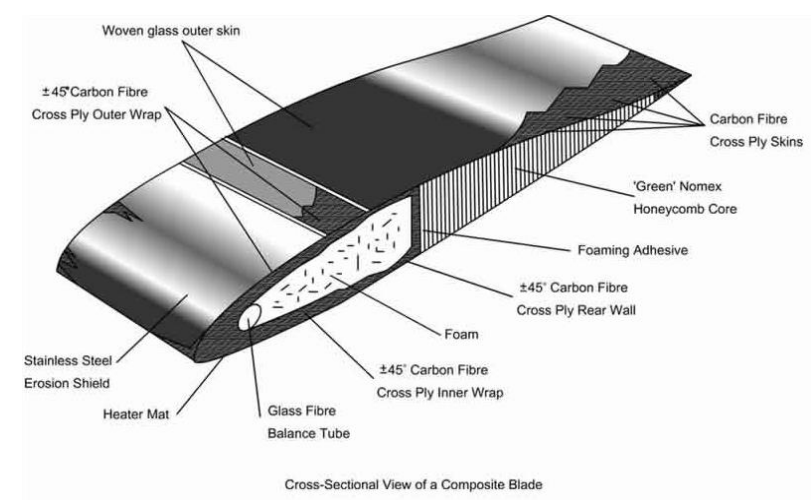

Cross section of Fan Blade
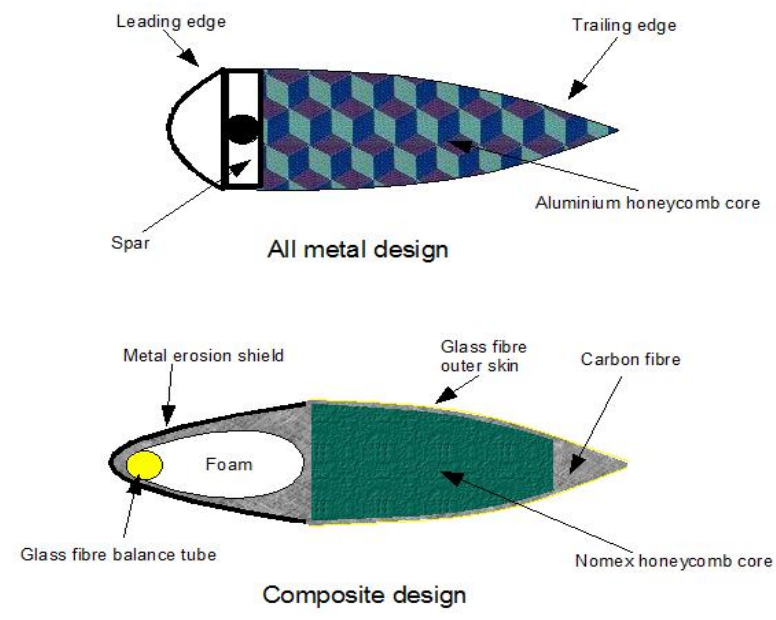

Comparison between metal and composite Fan Blade

Moreover, unlike metals, composite materials introduce the possibility to be optimized by specifically tailoring their characteristics, e.g. fibre orientations, constituent materials, ply thicknesses and ply stacking sequence, for a particular application. This introduces a high potential for innovative designs, but on the other hand adds considerable complexity to the design space. Advanced composites are becoming the material of choice for aircraft engine components. Using composite materials in aircraft engines enables manufacturers to reduce weight, and improve performance.

Advanced composite materials are made with either polymer-, metal- or ceramic matrix and high strength fibers. Polymer matrix composites (PMC) are attractive due to their low weight, high strength and low cost for manufacturing complex shaped components. The turbofan engine is a propulsive mechanism to combine the high thrust of a turbojet with the high efficiency of a propeller. Fig. 4 shows the cross section of composite fan blade it shown the fibre direction of composite to be $\pm 45^{\circ}$ but in this project the fibre direction is considered as $90^{\circ}$. Fig. shows the difference between all metal fan blade and a composite fan blade. In this project the honeycomb core in composite fan blade is still Aluminium in order to provide strength to the fan blade. 


\section{COMPOSITE FAN BLADE}

Aircraft and aircraft engine design have always strived for reduced weight and greater Efficiency. Other factors affecting aircraft and engine design involve cost and size, including the maintenance of the aircraft and the engines. With increased emphasis in these areas, future aircraft are growing in size, requiring either more thrust from the engines or additional engines. Reduced maintenance costs and initial costs can be achieved by enlarging the engines and increasing the thrust provided by the engines rather than by increasing the number of engines. However, as the engines grow larger, weight reduction becomes paramount as larger engines require larger, and therefore, heavier components.

Titanium is a common high strength material used in fan blades, but is undesirably expensive. A solid titanium fan blade can be readily manufactured, yet has a correspondingly high weight which adds to the centrifugal loads generated during operation. Hollow titanium fan blades are also known for reducing weight while maintaining strength, but increase the complexity of blade manufacture and associated costs. Thus, a hollow titanium blade has minimum weight with suitable high strength yet is very expensive to manufacture. Another form of a titanium fan blade is the hybrid fan blade which is primarily solid titanium with weight reducing pockets formed therein which may be filled with a lightweight, nonstructural filler material to complete the aerodynamic profile of the blade. The hybrid titanium blade is less expensive to manufacture than hollow titanium blades yet does not provide the greater weight reductions of the hollow titanium blade. Hence design methods and/or alternate materials may be a key to weight reduction, while reducing costs.

\section{MODELING AND FINEIT ELEMENT ANALYSIS}

\section{INTRODUCTION TO CAD}

Computer-aided design (CAD) is using pc structures (or workstations) to resource within the advent, modification, evaluation, or optimization of a format. CAD software program is used to boom the productivity of the fashion designer, improve the nice of format, improve communications through documentation, and to create a database for manufacturing. CAD output is regularly within the shape of electronic documents for print, machining, or different manufacturing operations. The time period CADD (for Computer Aided Design and Drafting) is also used. Its use in designing virtual systems is called digital design automation, or EDA. In mechanical design its miles called mechanical format automation (MDA) or pc-aided drafting (CAD), which includes the approach of creating a technical drawing with the use of computer software.

\section{INTRODUCTION TO PRO/E or CREO}

$P R O / E$ is the industry's de facto standard 3D mechanical design suit. It is the world's leading CAD/CAM /CAE software, gives a broad range of integrated solutions to cover all aspects of product design and manufacturing. Much of its success can be attributed to its technology which spurs its customer's to more quickly and consistently innovate a new robust, parametric, feature based model. Because that $P R O / E$ is unmatched in this field, in all processes, in all countries, in all kind of companies along the supply chains.PRO/E is also the perfect solution for the manufacturing enterprise, with associative applications, robust responsiveness and web connectivity that make it the ideal flexible engineering solution to accelerate innovations. $P R O / E$ provides easy to use solution tailored to the needs of small medium sized enterprises as well as large industrial corporations in all industries, consumer goods, fabrications and assembly. Electrical 
and electronics goods, automotive, aerospace, shipbuilding and plant design. It is user friendly solid and surface modeling can be done easily.

\section{INTRODUCTION TO ANSYS PROCEDURE FOR ANSYS}

Static analysis is used to determine the displacements stresses, stains and forces in structures or components due to loads that do not induce significant inertia and damping effects. Steady loading in response conditions are assumed. The kinds of loading that can be applied in a static analysis include externally applied forces and pressures, steady state inertial forces such as gravity or rotational velocity imposed (non-zero)displacements, temperatures (for thermal strain). A static analysis can be either linear or non linear. In our present work we consider linear static analysis.

The procedure for static analysis consists of these main steps

$>$ Building the model

$>$ Obtaining the solution

$>$ Reviewing the results.

\section{MODELING AND MESHING OF FAN BLADE}

A standard $1000 \mathrm{~mm}$ radius fan blade is selected as shown in Fig. and honeycomb structure is introduced.

\section{MODELLING}

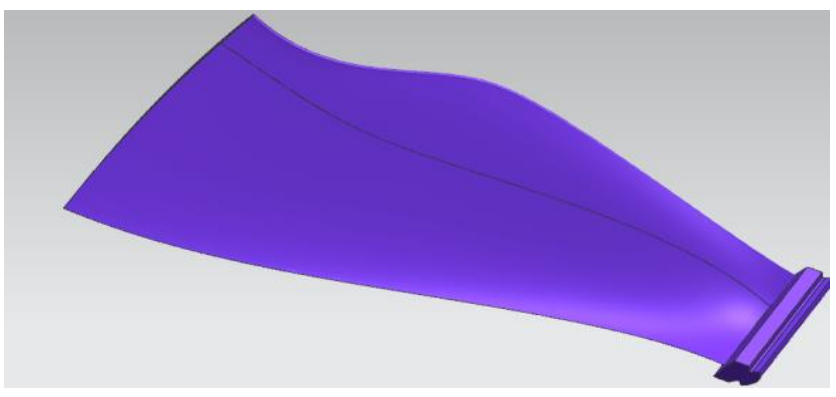

Fan Blade CAD Model

Step1: Fan blade is made hollow as shown in Fig.

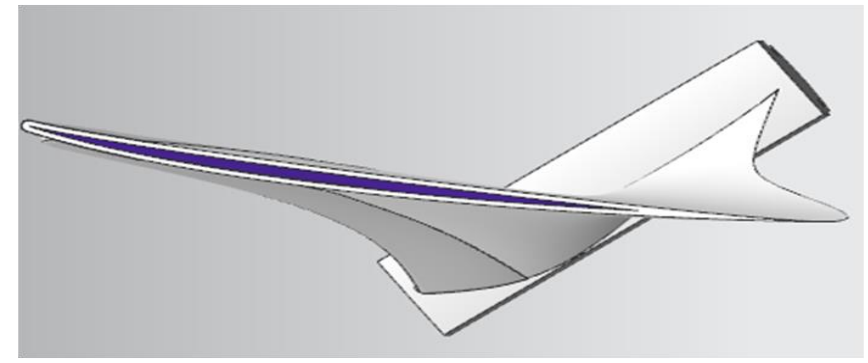

Hollow Fan Blade

Step 2: A fine honeycomb mesh is drawn as sketch and swept along the fan blade as shown in Fig.

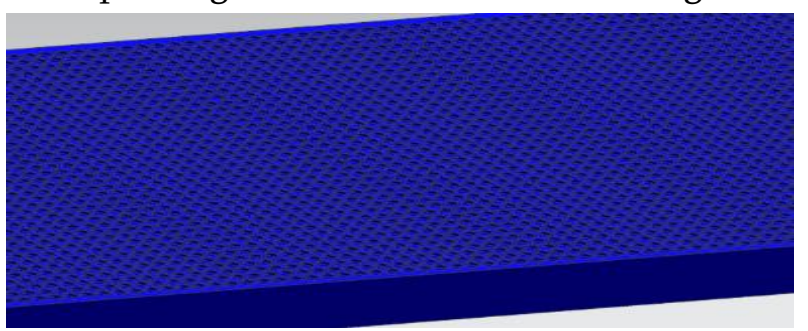

Honeycomb Structure

Step 3: Finally the honeycomb fan blade is obtained by trimming out extra surfaces as shown in Fig.

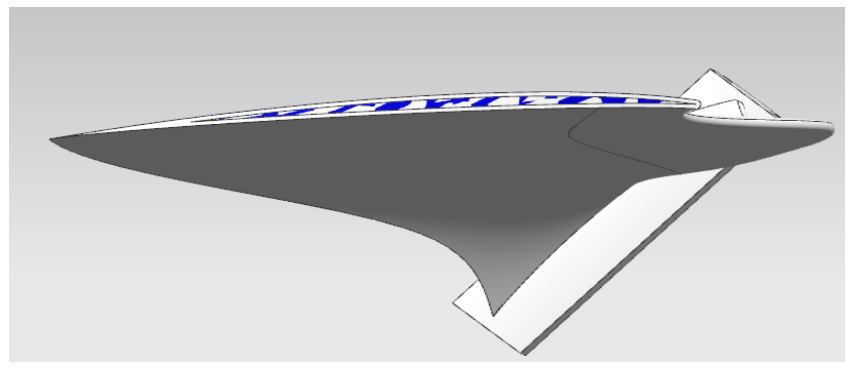

Honeycomb Fan Blade.

\section{MESHING GEOMETRY}

Save creo Model as .Iges format

$\rightarrow \rightarrow$ Ansys $\rightarrow$ Workbench $\rightarrow$ Select evaluation device

$\rightarrow$ static structural $\rightarrow$ double click

$\rightarrow \rightarrow$ Select geometry $\rightarrow$ proper click on $\rightarrow$ import geometry $\rightarrow$ pick out browse $\rightarrow$ open element $\rightarrow$ good enough

$\rightarrow \rightarrow$ Select mesh on work bench $\rightarrow$ proper click on $\rightarrow$ edit

Double click on geometry $\rightarrow$ choose MSBR $\rightarrow$ edit cloth $\rightarrow$ 


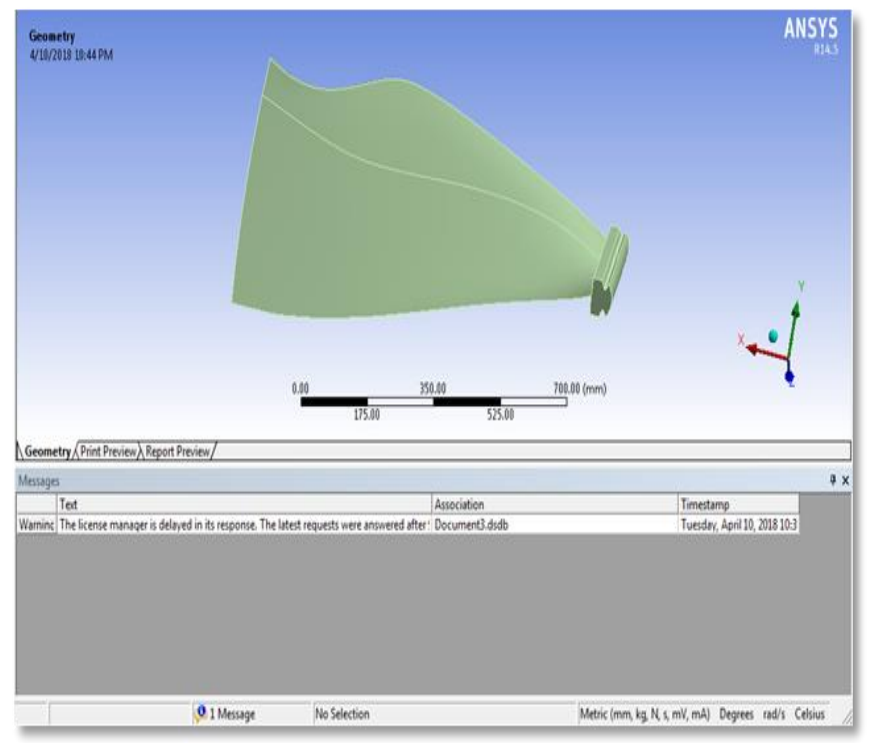

IGES Model in ANSYS

Fig. shows the imported .IGES solid model in ANSYS. Select mesh on left side part tree $\rightarrow$ right click $\rightarrow$ generate mesh $\rightarrow$

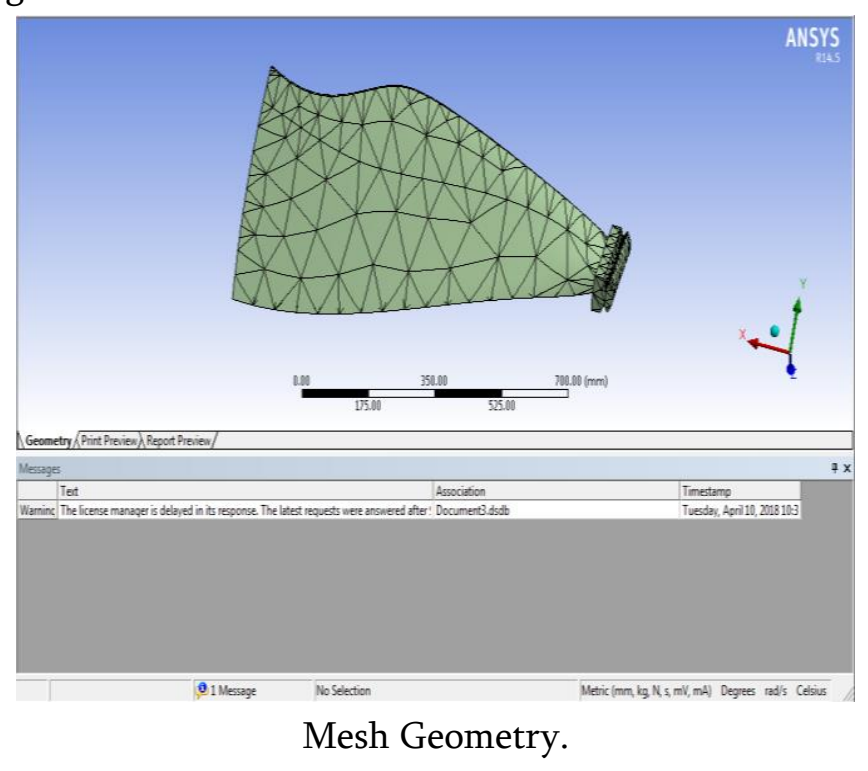

Fig. shows the mesh geometry of Fan Blade. Here simple mesh in generated for this model as with fine mesh it would be difficult to get solution for such a complex geometry.

Select static structural right click on $\rightarrow$ insert $\rightarrow$ pick rotational velocity and stuck assist $\rightarrow$ Select displacement $\rightarrow$ select required area $\rightarrow$ click on practice $\rightarrow$ positioned $\mathrm{X}, \mathrm{Y}, \mathrm{Z}$ factor $0 \rightarrow$

Select pressure $\rightarrow$ pick required place $\rightarrow$ click on follow $\rightarrow$ enter rotational speed

Select solution proper click on $\rightarrow$ remedy $\rightarrow$
Solution right click on $\rightarrow$ insert $\rightarrow$ deformation $\rightarrow$ general $\rightarrow$ Solution proper click on $\rightarrow$ insert $\rightarrow$ strain $\rightarrow$ equivalent (von-mises) $\rightarrow$

Solution proper click $\rightarrow$ insert $\rightarrow$ stress $\rightarrow$ equivalent (von-mises) $\rightarrow$

Right click on on deformation $\rightarrow$ examine all result

\section{RESULTS AND ANALYSIS}

\section{STATIC ANAL YSIS OF FAN BLADE}

Materials - Titanium Alloy (Ti-64)

Young's modulus $=113000 \mathrm{mpa}$

Poisson's ratio $=0.37$

Density $=\quad 4429 \mathrm{~kg} / \mathrm{mm} 3$

\section{MATERIAL-TITANIUM ALLOY}

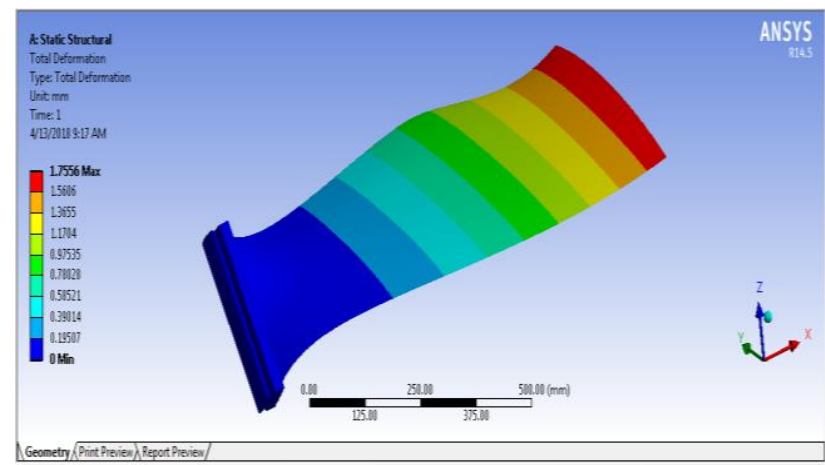

Statistical Analysis Total Deformation (Ti-64)

Result for total deformation is shown in Fig. It is observed that the deformation is more at the tip of the blade. It is because the mach. number is more at the tip of the blade. Maximum deformation value is observed as $1.7556 \mathrm{~mm}$.

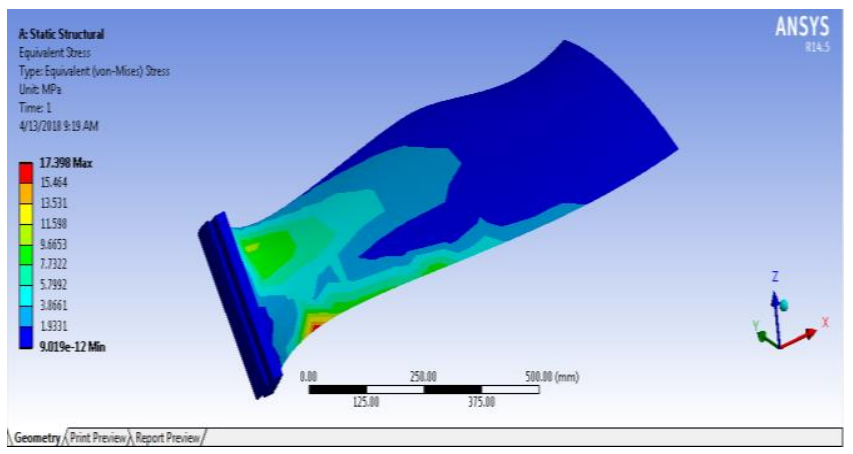

Statistical Analysis Von-mises Stress (Ti-64) 
Fig. shows result Equivalent stress (Von-mises) in the fan blade. It is observed more stress is formed near to the root of the blade. The maximum stress value is observed as $17.398 \mathrm{MPa}$.

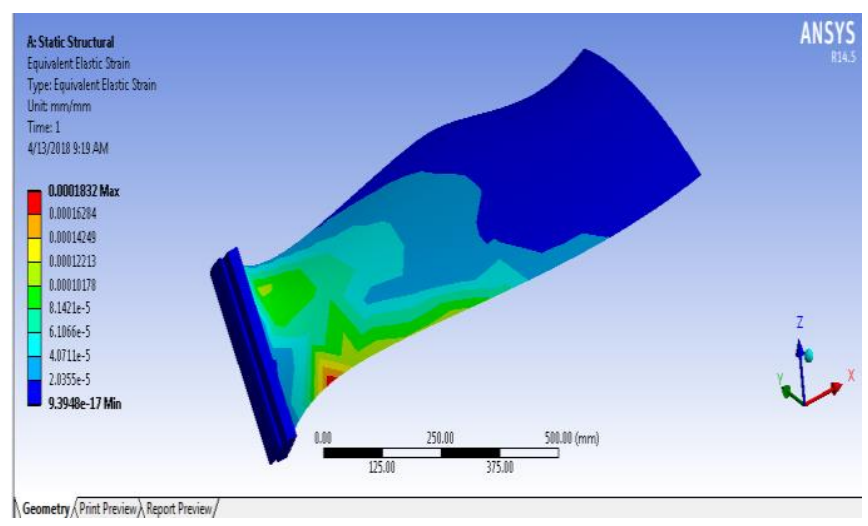

Statistical Analysis Von-mises Strain (Ti-64)

Equivalent elastic strain is more where the stress formation is more as shown in Fig. The maximum value of Elastic strain is observed as 0.0001832 $\mathrm{mm} / \mathrm{mm}$.

\section{MATERIAL-HONEY COMB FAN BLADE}

Materials - Honey Comb Fan blade

Young's modulus $=\quad 70000 \mathrm{mpa}$

Poisson's ratio $=0.83$

Density $=1600 \mathrm{~kg} / \mathrm{mm} 3$

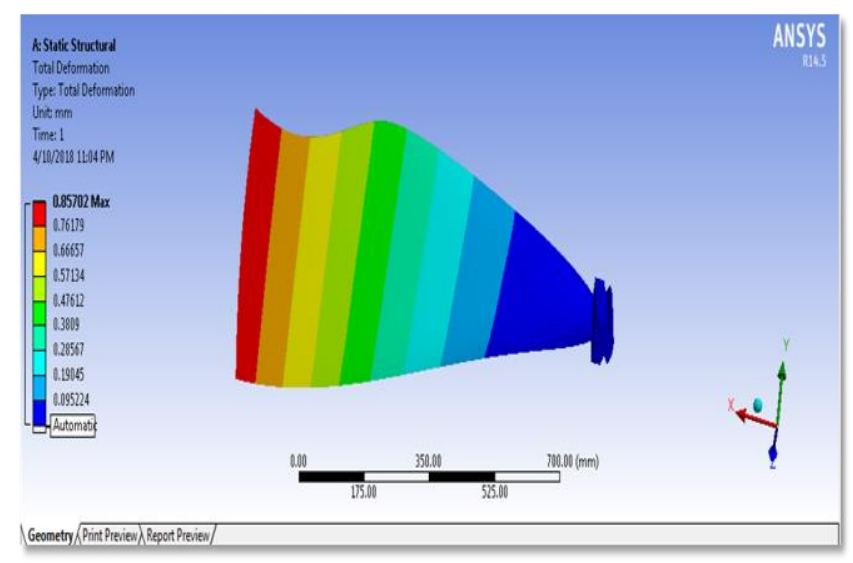

Statistical Analysis Total Deformation (Honey Comb Fan Blade)

Result for total deformation is shown in Fig. It is observed that the deformation is more at the tip of the blade. It is because the mach. number is more at the tip of the blade. Maximum deformation value is observed as $0.85702 \mathrm{~mm}$. The deformation is less for composite fan blade compared to Ti-64 fan blade which is $1.7556 \mathrm{~mm}$. It is because Composites stiffer than metal.

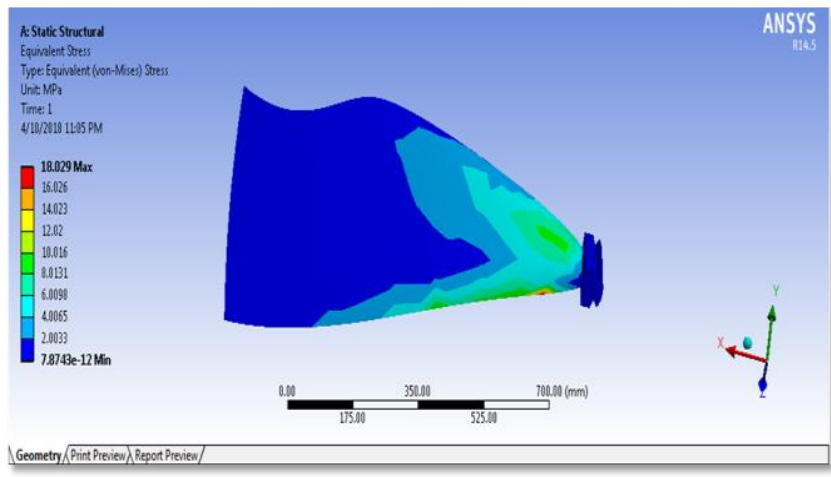

Statistical Analysis Von-mises Stress (Honey Comb Fan Blade)

Fig. shows result Equivalent stress (Von-mises) in the fan blade. It is observed more stress is formed near to the root of the blade. The maximum stress value is observed as $18.029 \mathrm{MPa}$. Here the stress is more compared to Ti-64 fan blade.

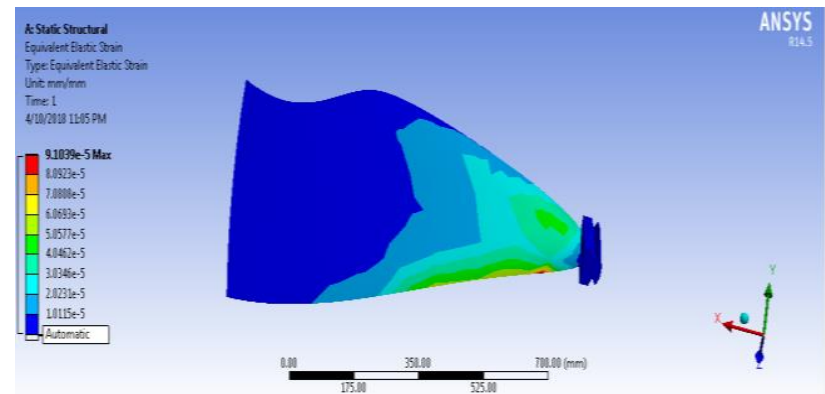

Statistical Analysis Von-mises Strain (Honey Comb Fan Blade)

Equivalent elastic strain is more where the stress formation is more as shown in Fig. The maximum value of Elastic strain is observed as 9.1039 e-5 $\mathrm{mm} / \mathrm{mm}$. Strain is lesser when compared Ti-64 Fan blade. 


\section{MODAL ANAL YSIS OF COMPOSITE FAN BLADE}

Modal analysis is conducted 3 mode shapes and the results are shown below.

\section{MATERIAL-TITANIUM ALLOY}

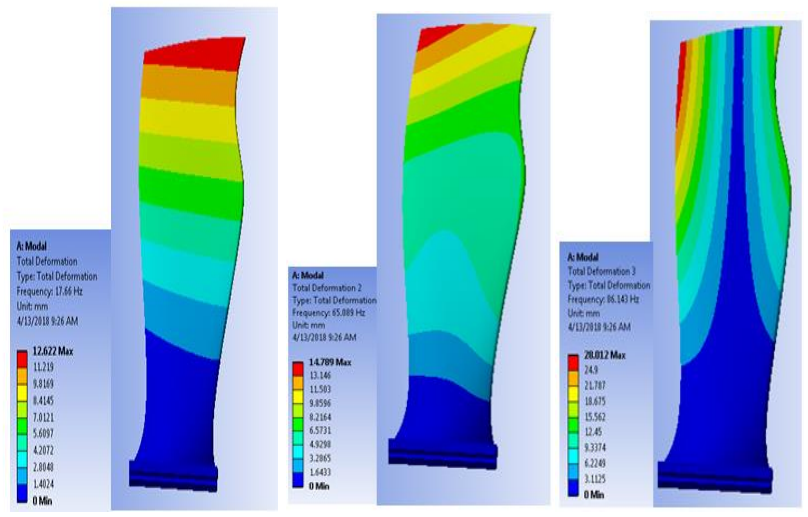

Total Deformation 1,2,3

Fig. Modal Analysis (Ti-64)

Modal analysis results for Ti-64 are shown in Fig. Total deformation max value at 3 mode shapes are $12.622 \mathrm{~mm}, 14.789 \mathrm{~mm}$ and $28.012 \mathrm{~mm}$ respectively.

\section{MATERIAL-HONEY COMB STRUCTURE}

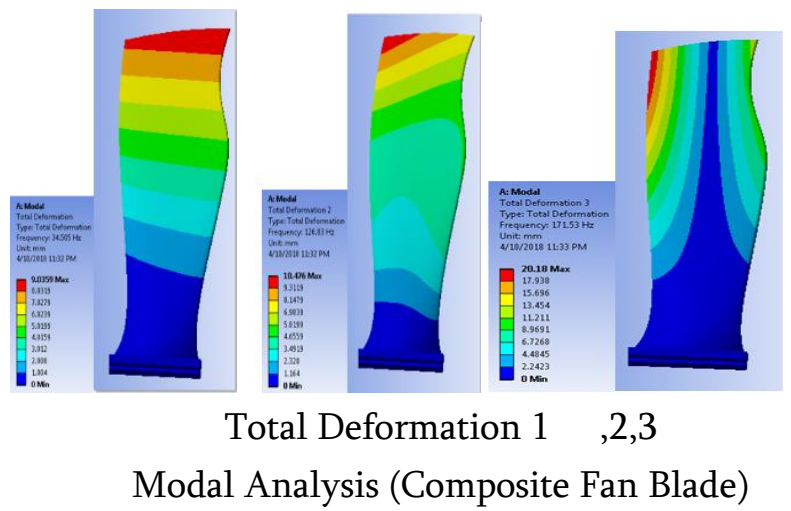

Modal analysis for Composite fan blade is shown in above figures. Total deformation max value at 3 mode shapes are $9.0359 \mathrm{~mm}, 10.476 \mathrm{~mm}$ and $20.18 \mathrm{~mm}$ respectively. Total deformation values are lesser when compared with Ti-64 fan blade.

\section{DYNAMIC ANALYSIS OF COMPOSITE FAN $B L A D E$}

Dynamic analysis is conducted for Fan Blade for three time periods. Results are shown below.

\section{At Time -10 Seconds}

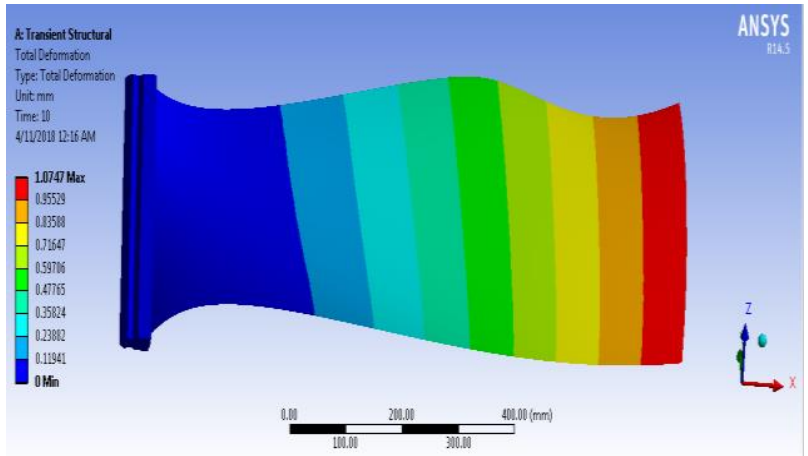

Dynamic Analysis Total Deformation (10S)

At time 10Sec. it is observed that the maximum deformation value is $1.0747 \mathrm{~mm}$ as shown in Fig.

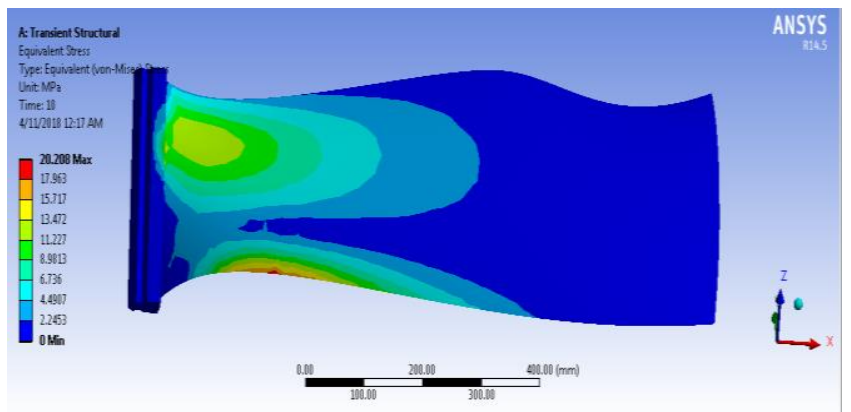

Dynamic Analysis Von-mises Stress (10S)

Maximum equivalent stress at time 10Sec. can be observed Fig. The maximum value of equivalent stress is $20.208 \mathrm{MPa}$.

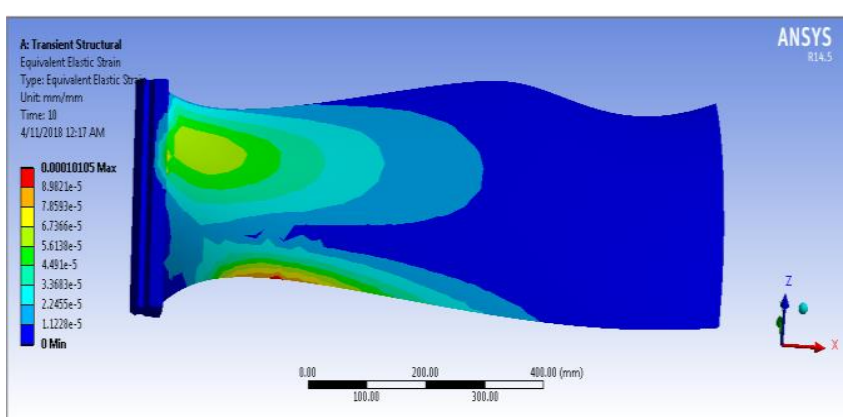

Dynamic Analysis Von-mises Strain (10S) 
Fig. shows strain distribution in composite fan blade. The maximum equivalent strain value at time $10 \mathrm{Sec}$. is observed as $0.00010105 \mathrm{~mm} / \mathrm{mm}$.

\section{At Time -20 Seconds}

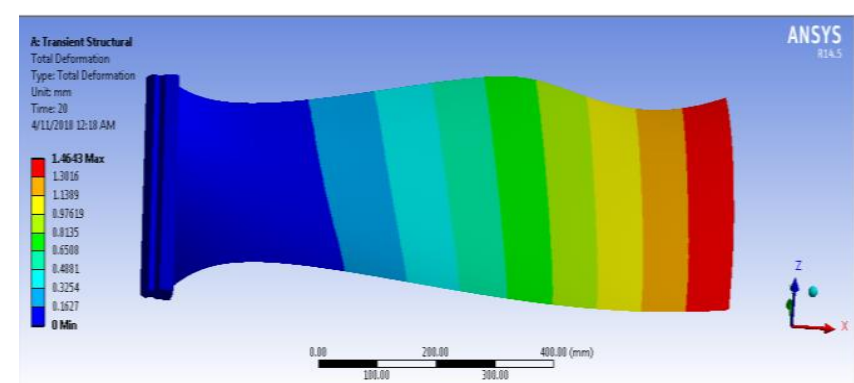

Dynamic Analysis Total Deformation (20S).

At time 20Sec. it is observed that the maximum deformation value is observed as $1.4643 \mathrm{~mm}$ as shown in Fig.

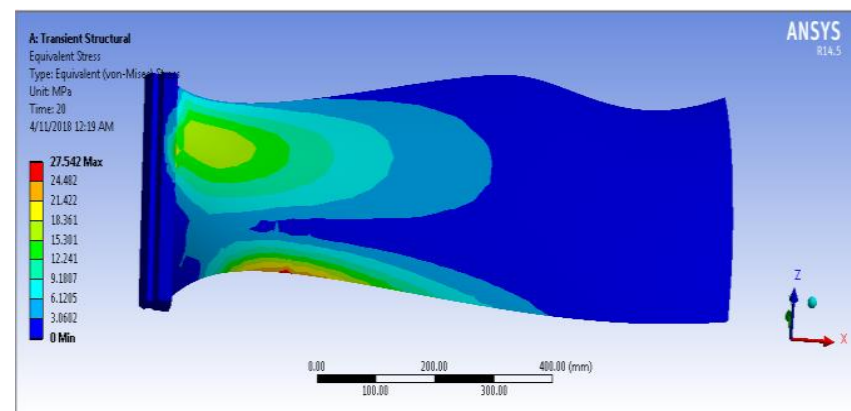

Dynamic Analysis Von-mises Stress (20S)

Maximum equivalent stress at time 20Sec. can be observed in Fig. The maximum value of equivalent stress is $27.542 \mathrm{MPa}$.

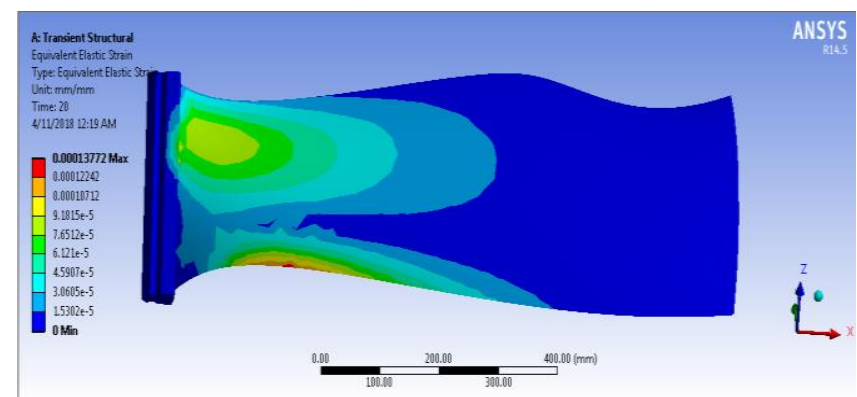

Dynamic Analysis Von-mises Strain (20S)

Fig. shows strain distribution in composite fan blade. The maximum equivalent strain value at time $20 \mathrm{Sec}$. is observed as $0.00013772 \mathrm{~mm} / \mathrm{mm}$.

\section{At Time -30 Seconds}

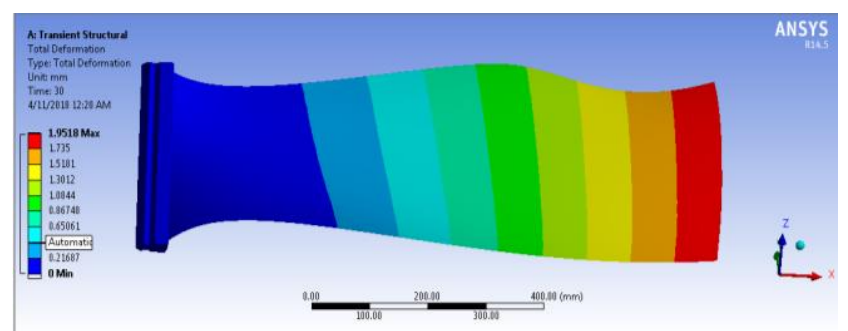

Dynamic Analysis Total Deformation (30S)

At time 30Sec. it is observed that the maximum deformation value is observed as $1.9518 \mathrm{~mm}$ as shown in Fig.

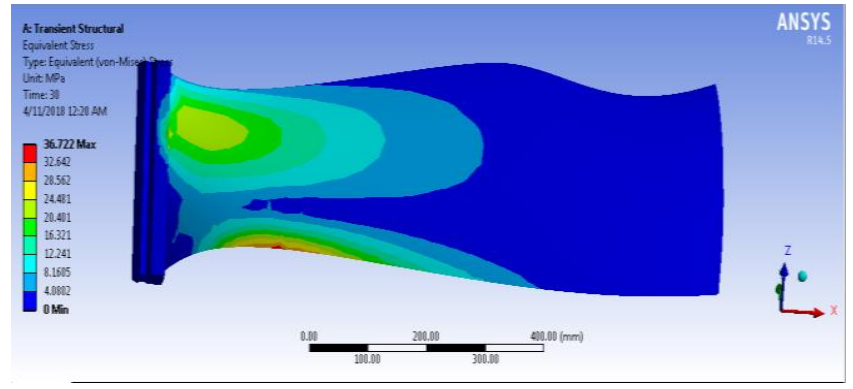

Dynamic Analysis Von-mises Stress (30S)

Maximum equivalent stress at time 30Sec. can be observed in Fig. The maximum value of equivalent stress is $36.722 \mathrm{MPa}$.

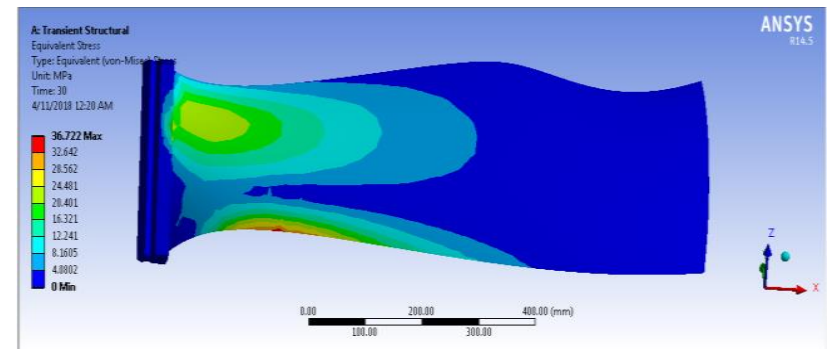

Dynamic Analysis Von-mises Strain (30S)

Fig. shows strain distribution in composite fan blade. The maximum equivalent strain value at time $30 \mathrm{Sec}$. is observed as $0.0001775 \mathrm{~mm} / \mathrm{mm}$.

\section{RESULT TABLES}

Table 1: Static Analysis Results

\begin{tabular}{|c|c|c|c|}
\hline $\begin{array}{c}\text { MATERIA } \\
\text { L }\end{array}$ & $\begin{array}{c}\text { DEFORMATION } \\
(\mathrm{mm})\end{array}$ & $\begin{array}{c}\text { STRESS } \\
(\mathrm{N} / \mathrm{mm} 2)\end{array}$ & $\begin{array}{c}\text { STRAI } \\
\mathbf{N}\end{array}$ \\
\hline Ti-64 & & & 0.0001 \\
& 1.7556 & 17.398 & 83 \\
\hline HONEY & & & \\
COMB & & & \\
FAN & & & $9.10 \mathrm{E}-$ \\
BLADE & 0.85702 & 18.029 & 05 \\
\hline
\end{tabular}


Table 2 : Modal Analysis Results

\begin{tabular}{|c|c|c|c|c|c|c|}
\hline $\begin{array}{l}\text { MATE } \\
\text { RIAL }\end{array}$ & $\begin{array}{c}\text { Mo } \\
\text { de } \\
1\end{array}$ & $\begin{array}{c}\text { Frequ } \\
\text { ency }\end{array}$ & $\begin{array}{c}\text { Mo } \\
\text { de } \\
2\end{array}$ & $\begin{array}{l}\text { Frequ } \\
\text { ency }\end{array}$ & $\begin{array}{c}\text { Mo } \\
\text { de } \\
3\end{array}$ & $\begin{array}{l}\text { Frequ } \\
\text { ency }\end{array}$ \\
\hline Ti-64 & $\begin{array}{l}12 . \\
622\end{array}$ & 17.66 & $\begin{array}{l}14 . \\
789\end{array}$ & 65.889 & $\begin{array}{l}28 . \\
012\end{array}$ & 86.143 \\
\hline $\begin{array}{c}\text { HONE } \\
\text { Y } \\
\text { COMB } \\
\text { FAN } \\
\text { BLAD } \\
\text { E }\end{array}$ & $\begin{array}{r}9.0 \\
359\end{array}$ & 34.505 & $\begin{array}{c}10 . \\
476\end{array}$ & 126.83 & $\begin{array}{c}20 \\
18\end{array}$ & 171.53 \\
\hline
\end{tabular}

Table 3: Dynamic Analysis Results

\begin{tabular}{|c|c|c|c|c|}
\hline $\begin{array}{c}\text { Materi } \\
\mathrm{al}\end{array}$ & $\begin{array}{c}\text { Time } \\
(\mathrm{S})\end{array}$ & $\begin{array}{c}\text { Deformatio } \\
\mathrm{n} \\
(\mathrm{mm})\end{array}$ & $\begin{array}{c}\text { Stress } \\
(\mathrm{N} / \mathrm{mm} 2\end{array}$ & Strain \\
\hline Honey & 10 & 1.0747 & 20.208 & 0.000102 \\
\cline { 2 - 5 } $\begin{array}{c}\text { Comb } \\
\text { Fan } \\
\text { Blade }\end{array}$ & 20 & 1.4643 & 27.542 & 0.000138 \\
\cline { 2 - 5 } & 30 & 1.9518 & 36.772 & 0.000178 \\
\hline
\end{tabular}

\section{CONCLUSION}

From results tables (Table 1 and Table 2) we can understand that $\mathrm{Ti}-64$ has better performance strength wise than that of honeycomb fan blade but there is only little difference. This is because young's modulus of composite is considered for 90 degrees fibre direction. Also honey comb structure in fan blade may have reduced the strength. Composite fan blade has less deformation compared to Ti-64 because composites are stiffer than metals and have good resistance to deformation. So, we can conclude that if the composite is considered as combination of layers of different fibre direction then the strength of composite will increase. Also the honeycomb structure different materials should be taken and analysis should be done to select better material as honeycomb core. For further development Fatigue analysis should be considered to understand better the performance of composite fan blade and also because more than $50 \%$ of failures in fan blade occur due to fatigue.

\section{REFERENCES}

[1]. Zhenzhen Liu1, Zhixiong Chen2, Jin Chen "The Strength Analysis of CFM56 Engine Blade" MATEC Web of Conferences 166, 04001 (2018)

[2]. H. C. TEICHMAN, R. N. TADROS “Analytical \& Experimental Simulation of Fan Blade Behaviour \& Damage Under Bird Impact" THE AMERICAN SOCIETY OF MECHANICAL ENGINEERS ^y 345 E. 47 St., New York, N.Y. 10017

[3]. Adam Kozakiewicz "Structural ultimate strength analysis of a first stage fan blade in a turbine jet engine RD-33" Volume: 232 issue: 1, page(s): 77-84, October 17, 2016; Issue published: January 1, 2018

[4]. James B Min, Louis J Ghosn and Bradley A Lerch "A study for stainless steel fan blade design with metal foam core" Journal of Sandwich Structures and Materials 2015, Vol. 17(1) 56-73

[5]. RAJEEV JAIN "Foreign Object Damage Analysis of Leading Edge of Fan Rotor Blade" SIMA (B) Department, Gas Turbine Research Establishment, C V Raman Nagar, Post Office Box : 9302, Bangalore 560 093, India (Received 25 February 2013; Accepted 18 April 2013)

[6]. J. I. G o a $\mathrm{t} \mathrm{h}$ a $\mathrm{m}$ "Materials problems in the design of compressor blades with fibrous composites "Proc. Boy. Soc. Lond. A. 319, 45-57 (1970)

[7]. Avinash Gudimetla "Optimum Material Evaluation of Fan Blades Using Reverse 
Engineering Approach" International Journal of Engineering Science Invention (IJESI) ISSN (Online): 2319 - 6734, ISSN (Print): 2319 6726

[8]. Srijith Bangaru "Advanced Material for Front Fan Blade Manufacturing" "Imperial Journal of Interdisciplinary Research (IJIR) 3(5):80 . January 2017 with1,790

[9]. Rula M. Coroneos "Structural Analysis and Optimization of a Composite Fan Blade for Future Aircraft Engine" 2012-09-20 | DOI: https://doi.org/10.1515/tjj-2012-0024

[10]. Binesh Philip "NUMERICAL ESTIMATION OF FATIGUE LIFE OF AEROENGINE FAN BLADES” SASTECH Journal, Volume 9, Issue 2, September 2010

[11]. YangBin "Blade containment evaluation of civil aircraft engines" Aeronautical Science \& Technology Research Institute of Commercial Aircraft Corporation of China, Beijing 102211, China

[12]. F. Gálvez "Materials behaviour and numerical simulation of a turbine blade-off containment analysis" Structures Under Shock and Impact IX 433

[13]. N. Sreenivasa Babu “Analysis of Turbine Blade under the Effect of Damping with Different Materials" Journal of Engineering Research and Applications, ISSN : 2248-9622, Vol. 4, Issue 1( Version 3), January 2014, pp.01-05
Cite this article as :

Polyminna Dileep, C. Mohan Naidu, "Strength Assessment of Fan Blade with Different Materials", International Journal of Scientific Research in Science and Technology (IJSRST), Online ISSN : 2395-602X, Print ISSN : 2395-6011, Volume 6 Issue 1, pp. 266-283, January-February 2019. Available at doi : https://doi.org/10.32628/IJSRST196138 Journal URL : http://ijsrst.com/IJSRST196138 